\title{
POTENSI RELUNG PASAR (MARKET NICHE) PRODUK SAYURAN PELAKU USAHA AGRIBISNIS SAYURAN SKALA KECIL
}

\author{
Sulistyodewi NW, Agriani H. Sadeli, Hesty N. Utami ${ }^{1)}$ \\ ${ }^{1)}$ Departemen Sosial Ekonomi Pertanian, Fakultas Pertanian, Universitas Padjadjaran \\ Jl. Raya Bandung-Sumedang Km 21 Jatinangor - Jawa Barat \\ Email: sulistyo.dewi@yahoo.com
}

\begin{abstract}
ABSTRAK
Kecamatan Ciwidey sebagai salah satu sentra produksi sayuran di Kabupaten Bandung memiliki banyak pelaku usaha agribisnis skala besar yang memasarkan hasil produksinya ke pasar tradisional di wilayah kota Bandung dan sekitarnya. Sebagian dari para pelaku agribisnis sayuran tersebut juga telah berhasil menjadi pemasok ke pasar modern. Kekuatan modal dan penguasaan informasi menjadi daya saing utama antara pelaku usaha sayuran skala besar, yang kedua hal ini justru menjadi hambatan bagi kesuksesan usaha pelaku agribisnis berskala kecil yang tergabung dalam kelompok tani yang bermodal usaha kecil dengan skala usaha produksi terbatas. Pendekatan relung pasar dimaksudkan untuk memperkecil persaingan di pasar, ditujukan untuk memuaskan kebutuhan pasar secara spesifik. Kajian potensi relung pasar produk sayuran ini dilakukan dengan pendekatan system thinking melalui SSM dengan tujuan mendapatkan gambaran permasalahan yang tidak terstruktur dan model pengembangan potensi yang adaptif dan aplikatif agar dapat dilakukan perbaikan di dunia nyata. Untuk menangkap peluang relung pasar, kelompok petani harus mengemas diri dan melakukan tindakan strategis bisnis berupa (1) melakukan pemasaran relasional; (2) melakukan peningkatan kualitas daun ketumbar dengan menawarkan daun ketumbar yang bersih dengan standar kualitas sesuai dengan permintaan serta menggunakan kemasan; (3) menjaga kontinuitas permintaan konsumen dengan menerapkan jadwal tanam; (4) mencari pasar potensial berupa relung pasar yang mampu memberikan peluang kesuksesan pemasaran yang lebih baik.
\end{abstract}

Kata kunci: relung pasar, petani, soft system methodology, sayuran

\begin{abstract}
Ciwidey sub-district is one of the vegetable production centers in Bandung with many large-scale agri-businesses that sell their products to the traditional market arround the area. Some of them also succeeded to penetrate the modern retail. Capital strength and mastery of information into key competitiveness among businesses large-scale vegetable, while this two factors become weakness for the success of small holders that limited to capital ownership and limited production. Niche market approach intended to minimize the market competition because it is objective to satisfy the needs of specific markets. Study of potential niche market vegetable products is analyzed using system thinking approach through the SSM to get an insight and overview of unstructured problems, adaptive development models and applicative potential in order to restructure and make improvement to the real world. The niche market opportunities should supplied by the farmers. The farmers need to applied business strategic actions (1) applied relationship marketing; (2) increase the quality by offering a packaged clean product with the quality standards in accordance with the market demand; (3) maintain continuity consumer demand by implementing a planting schedule; (4) search for potential markets such as niche markets that can provide opportunities of better marketing success.
\end{abstract}

Keywords: niche-market, farmer, soft system methodology, vegetables

\section{PENDAHULUAN}

Kecamatan Ciwidey merupakan salah satu sentra produksi sayuran di Kabupaten Bandung sejak beberapa tahun terakhir. Kecamatan yang berada pada ketinggian ratarata 1.100 meter dpl ini memiliki 7 desa yang tersebar di kurang lebih 3.533 Ha luas lahan kecamatan. Di Kecamatan Ciwidey terdapat beberapa pelaku usaha agribisnis sayuran skala besar yang menjadi pemasok bagi supermarket di kota-kota besar di Jawa Barat. Kekuatan modal dan penguasaan informasi menjadi daya 
saing utama para pelaku usaha sayuran skala besar dengan luas lahan diatas 5 Ha tersebut. Pada kondisi wilayah yang sama namun luas lahan jauh berbeda, di Kecamatan Ciwidey ternyata masih terdapat lahan-lahan sayuran sempit yang diusahakan oleh petani skala kecil. Petani skala kecil dengan permasalahan kedua hal yang dikuasai petani skala besar, keterbatasan modal dan tidak memiliki akses pasar dinilai menjadi hambatan bagi pelaku agribisnis berskala kecil yang tergabung dalam kelompok tani yang bermodal usaha kecil dengan kapasitas produksi minimal dan tujuan pasar terbatas.

Beberapa produk sayuran unggulan Kecamatan Ciwidey diantaranya bawang daun, kubis, seledri, sawi, dan tomat. Asparagus dan daun ketumbar merupakan komoditas yang saat ini sedang dirintis para petani skala kecil di Kecamatan Ciwidey mengingat permintaan ekspor kedua komoditas ini cukup tinggi berdasarkan informasi dari pemasok/eksportir yang didapatkan petani.

Tabel 1. Luas Lahan dan Produksi Sayuran di Kabupaten Bandung (2011)

\begin{tabular}{llrr}
\hline No & Kecamatan & $\begin{array}{r}\text { Luas Lahan } \\
(\mathrm{Ha})\end{array}$ & $\begin{array}{r}\text { Produksi } \\
(\mathrm{Kw})\end{array}$ \\
\hline 1 & Ciwidey & 757 & 105.716 \\
\hline 2 & Rancabali & 581 & 93.988 \\
\hline 3 & Pasirjambu & 530 & 66.640 \\
\hline 4 & Kertasari & 555 & 131.656 \\
\hline 5 & Lainnya & 724 & 97.702 \\
\hline & Total & 3.147 & 495.702 \\
\hline
\end{tabular}

Sumber: BPS, Kabupaten Bandung dalam Angka (2012).

Salah satu komoditas yang diusahakan oleh beberapa kelompok tani adalah daun ketumbar yang mudah dibudidayakan dan dilakukan secara tumpangsari bersama bawang daun dan seledri. Daun ketumbar belum banyak diminati konsumen lokal karena rasanya yang dinilai belum sesuai dengan karakteristik menumenu masakan Indonesia, namun dilihat dari budaya menu masakan di negara luar, daun ketumbar sangat diminati masyarakat Thailand, India, Meksiko, dan wilayah Eropa.

Saat ini daun ketumbar dipasarkan ke pasar tradisional dan bandar, namun permintaan masih rendah dan harga yang terima petani pun rendah. Selain permintaan dari pasar tradisional, permintaan datang dari supermarket di kota besar seperti Jakarta, Bandung, dan Surabaya. Permintaan kuantitas daun ketumbar dari supermarket masih rendah sehingga pasar ini bukan merupakan target market yang baik.
Selain itu permasalahan bisnis produk pertanian di sektor hulu adalah fluktuasi harga dan penurunan harga komoditas akibat perubahan iklim dan cuaca yang tidak menentu sehingga memaksa pelaku usaha pertanian di sektor hulu diantaranya petani produsen untuk mencari pasar lain untuk pemasaran komoditas yang mereka hasilkan sehingga mampu memberikan nilai tambah pemasaran yang lebih tinggi.

Salah satu cara untuk mendapatkan nilai tambah pemasaran adalah dengan melakukan inovasi pasar melalui diferensiasi pasar atau perluasan pasar yang dapat dilakukan dengan membidik ceruk pasar (niche market). Namun demikian, untuk menentukan ceruk pasar mana yang paling tepat untuk dimasuki oleh komoditas pertanian tertentu bukan yang mudah, karena pasar saat ini memiliki segmentasi yang sangat luas dengan permintaan pasar yang berbeda - beda dan menginginkan jenis komoditas pertanian dengan pertimbangan keinginan tertentu yang dimiliki oleh komodutas tersebut berdasarkan berbagai atribut komoditas yang beraneka ragam.

Peluang pasar yang berpotensi dengan permintaan daun ketumbar dalam kuantitas yang lebih tinggi dan harga yang lebih tinggi berasal dari usaha catering dan restoran hotel berbintang dengan sasaran konsumen akhir warga negara asing, belum dijadikan target pasar oleh para petani. Menurut Kotler (2003) market niche merupakan pasar yang memiliki karakteristik tidak menarik bagi pesaing dan memiliki pertumbuhan yang potensial untuk dipasarkannya sebuah produk yang memenuhi kebutuhan konsumen yang berbeda dan mampu untuk membayar dengan harga premium akan membawa keuntungan bagi produsen yang dapat menspesialisasikan produknya.

Membangun relung pasar (market niche) memberikan kesempatan pelaku usaha untuk menjual produk dan jasa kepada kelompok yang tidak ditujukan oleh pelaku usaha lainnya. Tantangan saat ini dan lingkungan usaha yang cepat mengalami perubahan menuntut sebuah inovasi untuk dapat mengembangkan suatu bisnis. Inovasi ini hanya dapat dicapai melalui spesialisasi, diferensiasi dan pemanfaatan peluang pasar baru seperti dalam relung pasar yang memiliki ukuran, laba dan potensi pertumbuhan (Abrar et al., 2009). Menurut Little et al (2010), kreativitas yang ditawarkan saluran pemasaran market niche muncul dari pemindahan konsumen produk pertanian organik dari pasar konvensional ke relung pasar. 
Relung pasar sayuran ini merupakan peluang yang harus dimanfaatkan oleh petani. Apabila petani skala kecil di Ciwidey dapat memasok daun ketumbar ke relung pasar tersebut, maka dapat meningkatkan harga jual produk daun ketumbar lokal petani sehingga meningkatkan pendapatan petani skala kecil di Ciwidey. Tetapi, untuk dapat memasarkan produknya ke pasar ini petani harus dapat mengemas diri dengan melakukan strategi yang tepat dalam menjalankan bisnisnya. Sehingga penelitian ini mencoba untuk mengkaji inovasi pasar melalui ceruk pasar untuk meningkatkan nilai tambah pemasaran serta cara-cara dan aktivitas yang dapat dilakukan dalam upaya untuk menembus ceruk pasar yang dapat dilakukan oleh petani produsen agribisnis ketumbar.

\section{METODE PENELITIAN}

Penelitian didesain secara kualitatif dengan metode studi kasus dan dilaksanakan di Kecamatan Ciwidey. Pemilihan lokasi dilakukan dengan pertimbangan sebagai salah satu sentra produksi sayuran di Kabupaten Bandung yang secara riil usahanya sebagian besar dikelola oleh petani skala kecil dengan luas lahan kurang dari satu hektar. Penentuan informan dilakukan secara purposive, yakni anggota Asosiasi Petani Sayuran Kabupaten Bandung (APSANBA) yang memiliki lahan kurang dari satu hektar. Pengumpulan data dilakukan dengan cara focus group discussion (FGD), wawancara mendalam (indepth interview) dan observasi. Data-data yang terkumpul kemudian dianalisis secara deskriptif. Menurut Mardikanto (2012), penelitian deskriptif bertujuan untuk menjelaskan, merinci, atau membuat deskripsi terhadap objek yang diteliti.

Dalam menganalisis potensi relung pasar produk sayuran bagi petani skala kecil digunakan cara berfikir sistem (system thinking) dengan soft system methodology (SSM). Pemodelan akan dapat membantu manusia untuk mengambil keputusan. Model ini yang akan digunakan sebagai bagian dari intervensi yang ditujukan untuk perbaikan sistem yang ada atau desain sistem yang baru. Kajian SSM bertujuan untuk menetapkan permasalahan dan model konseptual yang ada di dalamnya berperan sebagai pendukung pemahaman terhadap permasalahan agar dapat menghasilkan sebuah aksi nyata, kesepakatan, dan berbagi persepsi (Pidd, 2004).
Langkah pertama ialah memahami konsep yang berbeda dari perspektif yang menarik melalui rich picture. Konstruksi intelektual yang akan digunakan dalam analisis SSM terbangun melalui root definition (RD). $\mathrm{RD}$ yang akan menguraikan tujuan yang saling berkaitan menjadi model konseptual yang terdiri dari kegiatan terstruktur yang harus dilakukan untuk mencapai tujuan. Dengan demikian, RD mendefinisikan apa sistemnya dan model konseptual menjelaskan apa yang harus dilakukan sistem agar terdefinisi dengan baik (Wilson, 2001).

\section{HASIL DAN PEMBAHASAN}

Berdasarkan hasil FGD dengan pengurus Apsanba, diketahui pada umumnya pemasaran hasil panen sayuran petani skala kecil disalurkan ke pasar tradisional lokal dan bandar. Harga jual sayuran ditentukan oleh bandar. Para petani skala kecil ini tidak memiliki informasi harga di pasaran. Harga daun ketumbar yang dihasilkan petani di Kecamatan Ciwidey Rp. 25.000 per kg yang dijual ke supplier supermarket di Lembang.

Berdasarkan produksinya diketahui bahwa pada saat musim panen, hasi produksi dapat mencapai $20 \mathrm{~kg}$ per hari. Artinya, setiap 1 $\mathrm{kg}$ daun ketumbar dihasilkan dari sekitar 20 tanaman. Apabila luas lahan 1 ha maka dapat menghasilkan hingga 4-5 ton daun ketumbar. Jumlah petani skala kecil yang menanam daun ketumbar di satu desa hanya 10-15 orang, dan dalam satu kecamatan terdapat sekitar 50-60 orang petani daun ketumbar yang lahannya kurang dari 1 ha.

Kualitas sayuran sebenarnya masih dapat ditingkatkan apabila ada permintaan dari pembeli (buyer). Produk tergolong sayuran sehat, namun belum cukup organik. Kriteria sehat baru terlihat dari dosis pestisida yang rendah, namun lahan yang digunakan masih terkontaminasi praktik pertanian non organik. Penyeragaman kualitas produk sayuran belum dilakukan karena belum ada permintaan khusus dari bandar. Pada teknis budidaya, tingginya penyebaran hama dan penyakit pada tanaman hortikultura menyebabkan petani tidak dapat lepas dari penggunaan pestisida.

Pada proses pasca panen, sebagian besar petani skala kecil memasarkan produknya secara curah, hanya satu kelompok tani (kelompok tani Al Farizi) yang melakukan pasca panen (pembersihan, sortasi, pengikatan, grading serta pemberian kemasan plastik pada 
daun ketumbar). Hal ini dilakukan untuk dapat masuk ke pasar dengan permintaan kualitas tinggi. Terdapat 3 (tiga) grade daun ketumbar antara lain grade A, B, dan C. Grade A belum dihargai dengan layak oleh bandar/pemasok sehingga masih disamakan dengan grade $\mathrm{B}$. Pada daun ketumbar grade $\mathrm{C}$, petani langsung menjualnya ke pasar tradisional.

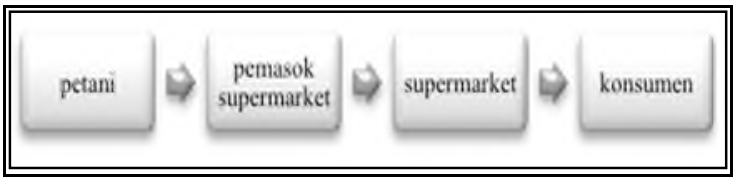

Gambar 1. Saluran Pemasaran Daun Ketumbar ke Supermarket

Pada saluran pemasaran daun ketumbar ke pasar tradisional, petani mengetahui informasi rendahnya permintaan dari bandar. Produk daun ketumbar berdasarkan hasil penjualan di pasar tradisional tidak banyak diminati pembeli disana.

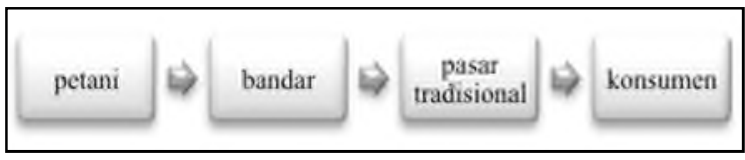

Gambar 2. Saluran pemasaran daun ketumbar ke pasar tradisional

\section{Analisis SSM dalam Pengembangan Bisnis Daun Ketumbar}

Analisis SSM diawali dengan perumusan kondisi masalah (problem situation) atau kondisi ideal, yakni petani skala kecil di Kecamatan Ciwidey memasarkan produk daun ketumbar ke market niche. Asosiasi Petani Sayuran Kabupaten Bandung berperan untuk mewadahi informasi yang dibutuhkan buyer (pembeli) produk daun ketumbar dengan produksi petani skala kecil di Kecamatan Ciwidey. Analisis selanjutnya adalah Rich picture yang merepresentasikan konsep dan hubungan melalui gambar dan simbol yang memiliki makna informasi namun tidak terstruktur. Pembuatan rich picture dapat dilakukan berulang-ulang hingga mendekati kondisi sebenarnya yang dialami oleh para aktor atau pelaku. (Gambar 3).

Terakhir adalah analisis budaya yang meliputi: (1) analisis intervensi, yakni refleksi atas penerapan Soft System Methodology dengan situasi masalah. Harapan petani sayuran skala kecil adalah peningkatan pendapatan dan menghindari persaingan dengan petani sayuran skala besar. (2) analisis sistem sosial, terfokus pada peran, norma, dan nilai dalam situasi permasalahan. Tidak ada sistem sosial yang mengatur saluran pemasaran dalam rantai pelaku usaha agribisnis hortikultura di Kecamatan Ciwidey. Belum adanya pemasaran relasional dalam rantai pasokan sayuran di Kecamatan Ciwidey; dan (3) dimensi politik, berkenaan dengan penyebaran kekuasaan (power) dalam situasi permasalahan. Diketahui bahwa hanya pelaku usaha skala besar yang dapat memasok produknya ke supermarket sedangkan pelaku usaha skala kecil hanya dapat menyalurkan produknya ke bandar atau pasar tradisional lokal. Apsanba tidak memiliki kekuasaan untuk mengatur saluran pemasaran karena anggota-anggotanya telah memiliki saluran pemasaran masing-masing sejak sebelum terbentuk asosiasi tersebut.

\section{Definition of Relevant System (CATWOE)}

Prinsip root definition (RD) antara lain memberikan pengertian $\mathrm{W}$ dalam CATWOE yakni diperkenankan mengawasi dan bertindak yang sesuai akan mengontrol interaksi yang terjadi. Struktur kata-kata dalam root definition teruji melalui CATWOE (Wilson, 2001). Pengembangan produk daun ketumbar bagi petani skala kecil untuk mengisi relung pasar produk sayuran premium. Kelompok tani Al Farizi Farm sebagai penggagas budidaya daun ketumbar mengambil peran sebagai pusat interaksi petani skala kecil terhadap aktivitas produksi dan pasca panen daun ketumbar di Kecamatan Ciwidey.

Tabel 2. CATWOE produk sayuran (daun ketumbar) di Kecamatan Ciwidey

\begin{tabular}{|c|c|c|}
\hline $\mathrm{C}$ & $\begin{array}{l}\text { Customer } \\
\text { (penerima } \\
\text { manfaat): }\end{array}$ & $\begin{array}{l}\text { Petani skala kecil di } \\
\text { Kecamatan Ciwidey }\end{array}$ \\
\hline A & $\begin{array}{l}\text { Actor (pelaku } \\
\text { transformasi): }\end{array}$ & Kelompok tani penggagas \\
\hline $\mathrm{T}$ & $\begin{array}{l}\text { Transformation } \\
\text { (perubahan): }\end{array}$ & $\begin{array}{l}\text { Menjual daun ketumbar ke } \\
\text { pasar premium }\end{array}$ \\
\hline $\mathrm{W}$ & $\begin{array}{l}\text { Weltanschauung } \\
\text { (perspektif } \\
\text { bermakna): }\end{array}$ & $\begin{array}{l}\text { Peningkatan kualitas daun } \\
\text { ketumbar dan penambahan } \\
\text { nilai dalam proses } \\
\text { pascapanen }\end{array}$ \\
\hline $\mathrm{O}$ & $\begin{array}{l}\text { Owner (pembatas } \\
\text { transformasi): }\end{array}$ & Kelompok tani penggagas \\
\hline $\mathrm{E}:$ & $\begin{array}{l}\text { Environment } \\
\text { constraints } \\
\text { (hambatan } \\
\text { lingkungan): }\end{array}$ & $\begin{array}{l}\text { Adanya petani skala kecil } \\
\text { yang tetap menjual ke } \\
\text { bandar pasar konvensional }\end{array}$ \\
\hline
\end{tabular}




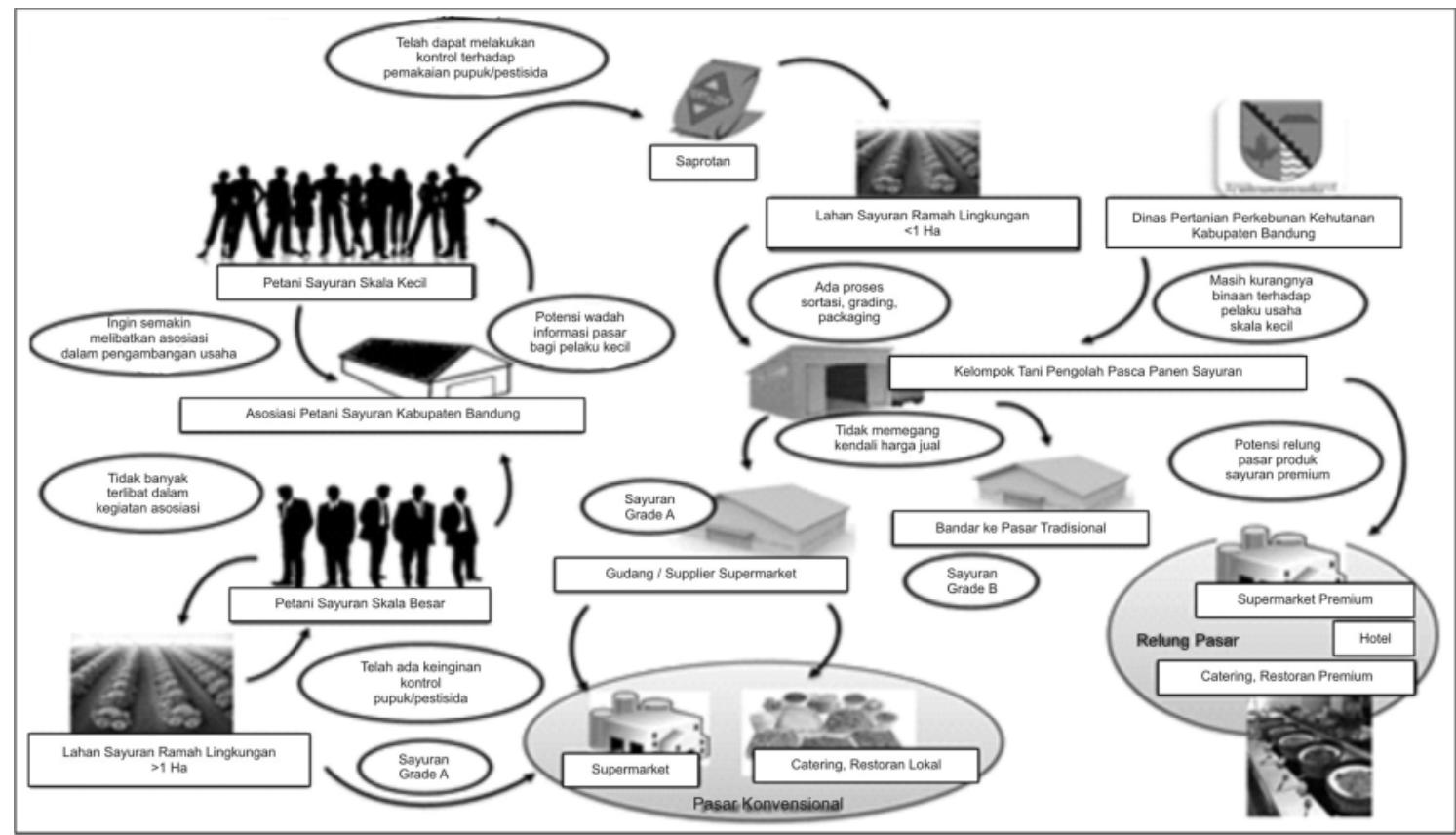

Gambar 3. Rich Picture Potensi Relung Pasar bagi Petani Kecil Sayuran

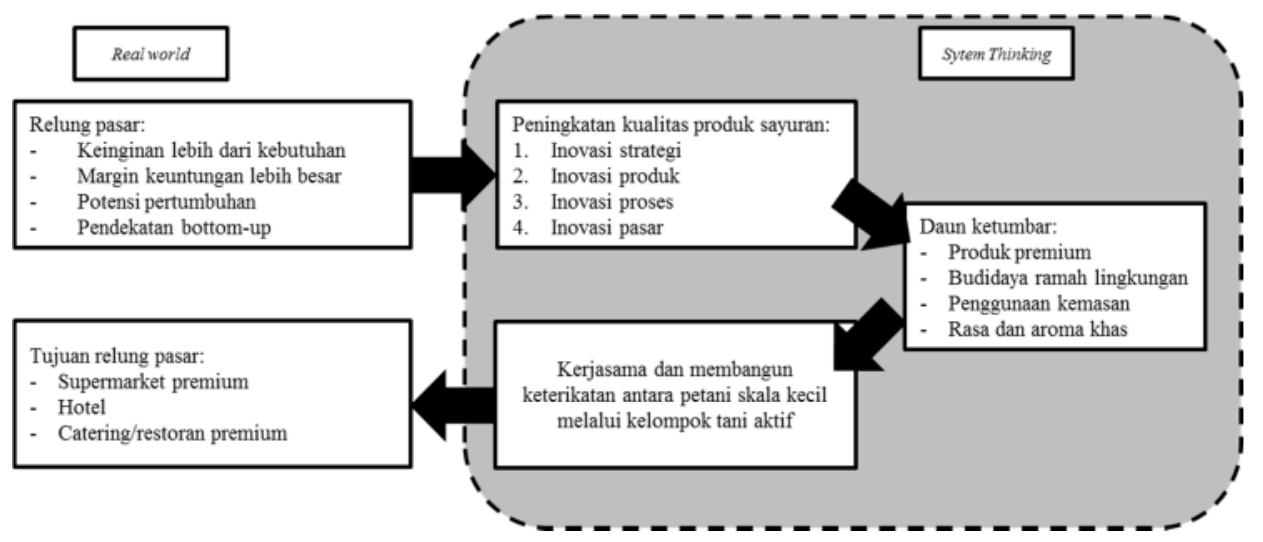

Gambar 4. Model Konseptual Petani Sayuran Kecil di Kecamatan Ciwidey

Tabel 3. Perbandingan Model dengan Dunia Nyata

\begin{tabular}{|c|c|c|}
\hline Aktivitas pada Model & Ada / Tidak & Kondisi Nyata \\
\hline Relung pasar & Tidak ada & $\begin{array}{l}\text { Pasar konvensional kebutuhan sehari-hari, tidak ada } \\
\text { perbedaan harga terhadap produk premium }\end{array}$ \\
\hline $\begin{array}{l}\text { Peningkatan kualitas produk } \\
\text { sayuran }\end{array}$ & Ada & $\begin{array}{l}\text { Petani selalu berusaha memproduksi produk yang ramah } \\
\text { lingkungan karena menghemat biaya pestisida }\end{array}$ \\
\hline $\begin{array}{l}\text { Daun ketumbar sebagai produk } \\
\text { premium }\end{array}$ & Tidak ada & Daun ketumbar diberlakukan sebagai sayuran biasa \\
\hline $\begin{array}{l}\text { Kerjasama dan membangun } \\
\text { keterikatan antara petani skala } \\
\text { kecil melalui kelompok tani aktif }\end{array}$ & Tidak ada & $\begin{array}{l}\text { Para petani skala kecil belum saling memiliki } \\
\text { keterikatan, tujuan pemasaran berbeda-beda }\end{array}$ \\
\hline Mencapai tujuan relung pasar & Tidak ada & $\begin{array}{l}\text { Pemasaran produk daun ketumbar sebatas pasar } \\
\text { tradisional dan pemasok supermarket }\end{array}$ \\
\hline
\end{tabular}

\section{Model Konseptual}

Formulasi 3E. E-pertama adalah efficacy, dengan proses: petani melakukan proses inovasi dalam pemasaran dan menghasilkan produk daun ketumbar kualitas baik melalui kerjasama dengan kelompok tani pengolah sayuran premium. E-kedua efficiency, dengan proses penerapan produksi ramah lingkungan yang tepat guna mendukung hasil panen optimal dan kualitas baik; dan E-ketiga adalah effectiveness, dengan proses koordinasi dengan produsen skala kecil melalui kelompok tani. Proses 
pemasaran dilakukan secara transparan langsung dengan buyer produk premium.

\section{Human Activity System (HAS)}

Analisis berikutnya adalah human activity system (HAS) yang merujuk pada aktivitas petani yang skala usahanya sangat kecil (sempit) untuk dapat mewujudkan transformasi usaha, yakni dengan cara meningkatkan kualitas produk sayuran dan menjualnya ke relung pasar (Gambar 3).

\section{Perbandingan Model}

Penulis membandingkan model konseptual dengan dunia nyata. (Tabel 3)

\section{Perumusan Perubahan}

Perubahan dapat dilakukan dengan tinjauan strategis. Pendekatan ini dinilai lebih efisien dan memanfaatkan pengetahuan mengenai proses saat ini untuk mengidentifikasi perubahan yang akan diadopsi (Wilson, 2001).

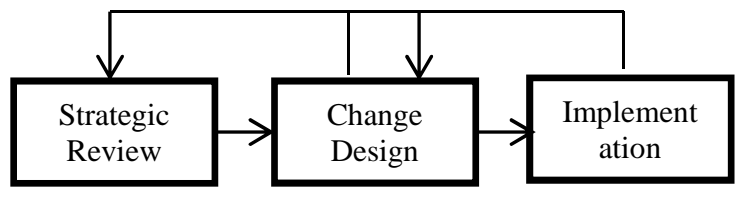

Gambar 5. Pendekatan Strategis (Wilson, 2001)

Inovasi strategi pada kelompok tani dilakukan dengan kerja sama antar oetani dengan membentuk kelompok tani, dimana kelompok tani ini melakukan pemasaran relasional dengan pihak pembeli secara langsung tanpa melalui perantara yaitu supermarket premium, catering dan restoran premium serta hotel berbintang. Membangun hubungan dengan suplier dan pelanggan merupakan salah satu cara untuk merupakan peluang untuk mendapatkan informasi berharga. Dalam membuat keputusan-keputusan bisnis (Claro, et.al., 2005). Dengan membangun kelompok tani yang memiliki relasi dengan pasar, maka dapat meningkatkan kemampuan petani dalam mengetahui informasi mengenai keinginan dan kebutuhan konsumen akan produk daun ketumbar. Informasi ini dapat dituliskan sebagai kontrak baik mengenai kualitas produk harga dan kuantitas yang diminta oleh konsumen. Selain itu menurut Gummesson (2008), dengan pemasaran relasional dapat meningkatkan keuntungan dengan melakukan interaksi di dalam jejaring usaha yang dapat membangun hubungan jangka panjang dan loyalitas konsumen. Inovasi produk dapat dilakukan dengan peningkatan kualitas produk agar dapat memenuhi kebutuhan dan keinginan konsumen sehingga tercipta kepuasan pembeli. Menurut Fawcett (2014), kualitas merupakan salah satu komponen kinerja yang mengukur kemampuan dalam menyampaikan produk dan jasa dimata konsumen yang lebih baik dibandingkan pesaing lain. Hal ini dapat dilakukan dengan menawarkan daun ketumbar yang baik dari segi kualitas, kebersihan dan kemasan. Inovasi dalam proses dilakukan untuk mendukung peningkatan kualitas produk melalui inovasi proses pada tahap budi daya dengan melakukan proses budi daya yang ramah lingkungan yang mengahsilkan produk bebas pestisida. Selain itu, pasca panen dengan dilakukan pembersihan serta sortasi dan grading pada produk daun ketumbar. Selain itu untuk pemenuhan kuntinuitas produk ke konsumen dilakukan penanaman yang disesuaikan dengan jadwal tanam yang mengikuti permintaan niche market sehingga produk dapat dipasok secara kontinyu.

Inovasi pasar pada kajian ini adalah dengan memperluas pasar atau menspesifikan pasar dengan membidik relung pasar yang dapat dilakukan oleh petani sayuran khususnya untuk komoditas ketumbar diantaranya dengan memasuki relung pasar untuk food services diantaranya restoran premium dan ritel modern yang berkelas premium. Inovasi pasar berupa relung pasar dapat mengurangi permasalahan petani sayuran untuk bersaing di dalam pasar yang sebagian besar bersaing di pasar tradisional atau pasar modern yang bukan berkelas premium sehingga petani hanya sebagai price-taker.Pengambilan tindakan perubahan usaha dilakukan pada jeda waktu implementasi dan langkah perbaikan. Hal ini diupayakan oleh pemangku kepentingan dengan kontrol dan pembinaan Pemerintah terhadap petani kecil sayuran pada umumnya.

\section{KESIMPULAN DAN SARAN}

Relung pasar yang dapat dimasuki petani komoditas ketumbar sebagai inovasi pasarnya adalah dengan memasarkan sayurannya ke pasar modern seperti supermaket premium, catering dan restoran premium serta hotel berbintang yang didalamnya terdapat konsumen masyarakat asing di Indonesia yang terbiasa menggunakan daun ketumbar dalam menu masakannya. Relung pasar 
ini belum banyak dituju oleh petani skala besar, sehingga persaingannya tidak ketat dan peluang masih terbuka lebar untuk mengisi pasar tesebut. Untuk menangkap peluang relung pasar ini kelompok petani harus mengemas diri dan melakukan tindakan-tindakan strategis bisnis berupa (1) melakukan pemasaran relasional; (2) melakukan peningkatan kualitas daun ketumbar dengan menawarkan daun ketumbar yang bersih dengan standar kualitas sesuai dengan permintaan serta menggunakan kemasan; (3) menjaga kontinuitas permintaan konsumen dengan menerapkan jadwal tanam; (4) mencari pasar potensial berupa relung pasar yang mampu memberikan peluang kesuksesan pemasaran yang lebih baik. Peningkatan kualitas produk dapat dilakukan dengan melakukan penyesuaian spesifikasi komoditas ketumbar yang dihasilkan sesuai dengan keinginan pasar sasaran serta membangun hubungan relasional dengan suplier dan calon pelanggan melalui pemasaran relasional.

\section{UCAPAN TERIMAKASIH}

Apresiasi dan penghargaan kami sampaikan kepada pengurus Asosiasi Petani Sayuran Kabupaten Bandung dan Kepala Bidang Hortikultura Dinas Pertanian, Perkebunan, dan Kehutanan Kabupaten Bandung.

\section{DAFTAR PUSTAKA}

Abrar, Muhammad, Zhilong Tian, Xinming Deng. 2009. Exploration of Niche Market and Innovation in Organic Textile by a Developing Country. International Journal of Business and Management Vol 4 No. 2 February.

Checkland, Peter, Jim Scholes. 1999. Soft Systems Methodology in Action. Michigan: Wiley.

Claro, Danny Pimentel, et., al. 2005. Relationship Marketing Strategies: When Buyer and Supplier Follow Different Strategies to Achieve Performance.
Brazilian Administration Review (BAR) v. 2, n. 2, art. 2, p. 17-34, july/dec. 2005.

Creswell, John W. 1994. Research Design: Qualitative and Quantitative Approaches. California: Sage Publications Inc.

Ginting,G. Open Innovation Model: Empowering Entrepreneurial Orientationand Utilizing Network Resources as Determinant for Internationalization Performance of Small Medium Agroindustry. Agriculture and Agriculture Science Procedia 3 (2015) www.sciencedirect.com33

Fawcett, Stanley E., Fawcett, Amydee M., SCCMP. 2014. The Definite Guide to Order Fulfillment and Customer Service: Principles and Strategies For Planning, Organizing, and Managing Fulfillment and Service Operations.

Gummesson, E. 2008. Total Relationship Marketing Third Edition. Elsevier: United Kingdom.

Kotler, Philip. 2003. Marketing Management. New Jersey: Prentice Hall.

Little, Ruth, Damian Maye, Brian Ilbery. 2010. Collective purchase: Moving Local and Organic Foods beyond The Niche Market. Environment and Planning vol. 42, May 2010.

Mardikanto, Totok. 2012. Metoda Penelitian dan Evaluasi Pemberdayaan Masyarakat. Solo: Program Studi Penyuluhan Pembangunan/ Pemberdayaan Masyarakat Program Pascasarjana Universitas Sebelas Maret.

Pidd, Michael. 2004. Systems Modelling: Theory and Practices. West Sussex: John Wiley \& Sons Ltd.

Wilson, Brian. 2001. Soft System Methodology: Conceptual Model Building and its Contribution. West Sussex: John Wiley \& Sons Ltd 